\title{
Expression of ck-19, galectin-3 and hbme-1 in the differentiation of thyroid lesions: systematic review and diagnostic meta-analysis
}

Leandro Luongo de Matos ${ }^{1,2,3,6^{*}}$, Adriana Braz Del Giglio ${ }^{4}$, Carolina Ogawa Matsubayashi ${ }^{4}$, Michelle de Lima Farah", Auro Del Giglio ${ }^{5}$ and Maria Aparecida da Silva Pinhal ${ }^{1,2}$

\begin{abstract}
Background: To distinguish between malignant and benign lesions of the thyroid gland histological demonstration is often required since the fine-needle aspiration biopsy method applied pre-operatively has some limitations. In an attempt to improve diagnostic accuracy, markers using immunocytochemistry and immunohistochemistry techniques have been studied, mainly cytokeratin-19 (CK-19), galectin-3 (Gal-3) and Hector Battifora mesothelial-1 (HBME-1). However, current results remain controversial. The aim of the present article was to establish the diagnostic accuracy of CK-19, Gal-3 and HBME-1 markers, as well as their associations, in the differentiation of malignant and benign thyroid lesions.
\end{abstract}

Methods: A systematic review of published articles on MEDLINE and The Cochrane Library was performed. After establishing inclusion and exclusion criteria, 66 articles were selected. The technique of meta-analysis of diagnostic accuracy was employed and global values of sensitivity, specificity, area under the summary ROC curve, and diagnostic odds ratio (dOR) were calculated.

Results: For the immunohistochemistry technique, the positivity of CK-19 for the diagnosis of malignant thyroid lesions demonstrated global sensitivity of $81 \%$ and specificity of $73 \%$; for Gal-3, sensitivity of $82 \%$ and specificity of $81 \%$; and for HBME-1, sensitivity of $77 \%$ and specificity of $83 \%$. The association of the three markers determined sensitivity of $85 \%$, specificity of $97 \%$, and diagnostic odds ratio of 95.1 . Similar results were also found for the immunocytochemistry assay.

Conclusion: This meta-analysis demonstrated that the three immunomarkers studied are accurate in pre- and postoperative diagnosis of benign and malignant thyroid lesions. Nevertheless, the search for other molecular markers must continue in order to enhance this diagnostic accuracy since the results found still show a persistency of false-negative and false-positive tests.

Virtual slides: Http://www.diagnosticpathology.diagnomx.eu/vs/3436263067345159

Keywords: Tumor markers, Biological, Galectin 3, Keratin 19, HBME-1 antigen, Thyroid, Review

\footnotetext{
*Correspondence: Imatos@amcham.com.br

'Biochemistry Department - Faculdade de Medicina do ABC, Santo André, Brazil

${ }^{2}$ Biochemistry Department - Universidade Federal de São Paulo, São Paulo,

Brazil

Full list of author information is available at the end of the article
} 


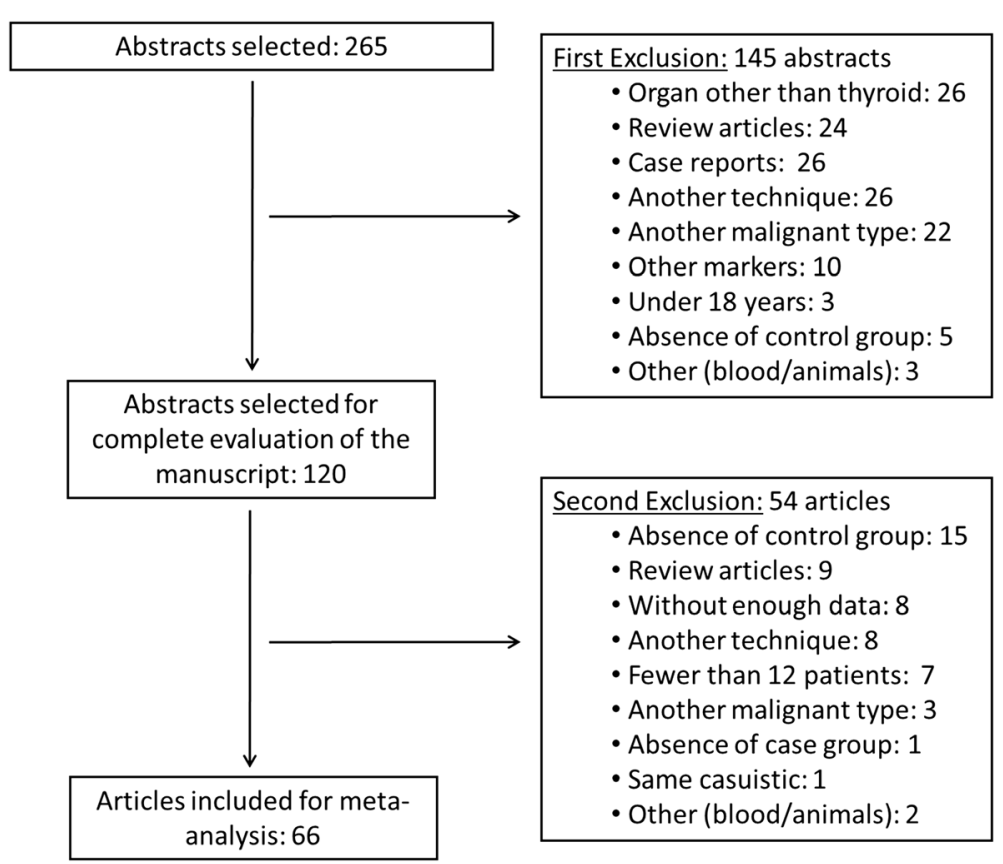

Figure 1 Flowchart of article selection.

\section{Introduction}

Thyroid gland carcinoma is a very prevalent neoplasia worldwide. A survey sponsored by the World Health Organization (WHO) in 2010 revealed that there are around 44,670 new cases and 1,690 deaths caused by this disease every year [1].

The majority of malignant lesions of the thyroid, such as papillary carcinoma, medullary carcinoma and undifferentiated histological types, can be diagnosed by cytological criteria using samples obtained by fine-needle aspiration biopsy (FNAB) guided by ultrasonography [2]. Likewise, the diagnosis of benign lesions, such as hyperplastic nodules, colloid nodules and auto-immune diseases like thyroiditis, can be cytologically established [3]. However, to distinguish between malignant and benign lesions histological demonstration is often required for a precise diagnosis. Therefore, they are cytologically grouped as undetermined tumors or suspected follicular neoplasia [4-7] and patients often undergo a diagnostic surgical procedure (thyroidectomy) even though the general carcinoma rate of this condition is very low [8]. Thus, the immunohistochemistry method plays a complementary role in the attempt to clarify this dilemma [9].

Many studies employ immunohistochemistry techniques as an attempt to search for markers involved in the genesis or specific characteristics of follicular patterned tumors. Among the immunocytochemistry (ICC) or immunohistochemistry (IHC) markers most employed to distinguish between benign and malignant lesions of the thyroid are: cytokeratin-19 (CK-19: a keratin member family responsible for the structural integrity of epithelial cells), galectin-3 (Gal-3: involved in the process of cell migration, adherence and apoptosis) and Hector

Table 1 Number of studies, patients and their distributions included in each analysis by the immunohistochemistry technique

\begin{tabular}{lcccccc}
\hline IHC ANALYSIS & Studies & Patients & TP & FP & FN & TN \\
\hline CK-19[10,14-33] & 21 & 3603 & $1697(47.1 \%)$ & $433(12.0 \%)$ & $314(8.7 \%)$ & $1159(32.2 \%)$ \\
GAL-3[10,14-17,19,21,25-56] & 39 & 5168 & $2270(43.9 \%)$ & $528(10.2 \%)$ & $408(7.9 \%)$ & $1962(38.0 \%)$ \\
HBME-1[10,14-19,21,24-27,29,30,41,51,57-61] & 21 & 3900 & $1501(38.5 \%)$ & $324(8.3 \%)$ & $436(11.2 \%)$ & $1639(42.0 \%)$ \\
CK-19+ HBME-1[14,17] & 2 & 157 & $84(53.5 \%)$ & $2(1.3 \%)$ & $14(8.9 \%)$ & $57(36.3 \%)$ \\
GAL-3+ CK-19[14,17] & 2 & 164 & $90(54.9 \%)$ & $6(3.7 \%)$ & $9(5.5 \%)$ & $59(36.0 \%)$ \\
GAL-3+ HBME-1[14,17,46,51] & 4 & 293 & $119(40.6 \%)$ & $15(5.1 \%)$ & $40(13.7 \%)$ & $119(40.6 \%)$ \\
GAL-3+ HBME-1+CK-19[14,17,29] & 3 & 231 & $121(52.4 \%)$ & $3(1.3 \%)$ & $22(9.5 \%)$ & $85(36.8 \%)$ \\
\hline
\end{tabular}

LEGEND: TP (true-positive), FP (false-positive), FN (false-negative) and TN (true-negative). 
Table 2 Sensitivity and specificity of each immunohistochemistry marker or association

\begin{tabular}{|c|c|c|c|c|c|c|}
\hline IHC ANALYSIS & Sensitivity $(95 \% \mathrm{Cl})$ & Q & $\mathbf{P}$ & Specificity $(95 \% \mathrm{Cl})$ & Q & $\mathbf{P}$ \\
\hline CK-19[10,14-33] & $0.81(0.79-0.83)$ & 192.02 & $<0.00001$ & $0.73(0.70-0.75)$ & 254.49 & $<0.00001$ \\
\hline GAL-3[10,14-17,19,21,25-56] & $0.82(0.81-0.84)$ & 341.95 & $<0.00001$ & $0.81(0.79-0.82)$ & 512.70 & $<0.00001$ \\
\hline HBME-1[10,14-19,21,24-27,29,30,41,51,57-61] & $0.77(0.76-0.79)$ & 298.64 & $<0.00001$ & $0.83(0.82-0.85)$ & 444.58 & $<0.00001$ \\
\hline CK-19+ HBME-1[14,17] & $0.86(0.77-0.92)$ & 0.41 & 0.5245 & $0.97(0.89-1.00)$ & 7.46 & 0.0063 \\
\hline GAL-3 + CK-19[14,17] & $0.91(0.83-0.96)$ & 0.01 & 0.9383 & $0.91(0.81-0.97)$ & 5.31 & 0.0212 \\
\hline GAL-3 + HBME-1[14,17,46,51] & $0.75(0.67-0.81)$ & 57.91 & $<0.00001$ & $0.89(0.82-0.94)$ & 7.46 & 0.0587 \\
\hline GAL-3 + HBME-1 + CK-19[14,17,29] & $0.85(0.78-0.90)$ & 0.25 & 0.8826 & $0.97(0.90-0.99)$ & 7.33 & 0.0256 \\
\hline
\end{tabular}

Battifora mesothelial-1 (HBME-1: an unelucidated membrane antigen that exists in the microvilli of the mesothelioma cells and also in follicular thyroid tumor cells) or their associations [10]. However, their results and applications are still controversial since these molecules have not proved to have specificity and - more critically, to avoid an eventual diagnostic thyroidectomy - enough sensitivity in the differentiation of follicular lesions because of persistent variable rates of, respectively, falsepositive and false-negative results [11].

In view of this, the objective of the present study was to establish the diagnostic accuracy of CK-19, Gal-3 and HBME-1 markers, and their associations, for the differentiation between benign and malignant thyroid lesions.

\section{Material and methods}

\section{Systematic review}

A search for articles published exclusively in the English language between January 2001 and December 2011 was carried out in the electronic databases MEDLINE and The Cochrane Library.

A wide strategy was employed in the search in order to avoid publication bias, and the following describers were used: ((ck-19 and thyroid) OR (galectin-3 and thyroid) OR (hbme-1 and thyroid)). Reference lists of previously obtained articles were also analyzed so that other relevant studies could be identified for inclusion in the present study.
The exclusion criteria adopted for both the study as a whole and for cases individually selected were as follows: inability to obtain individual data, review articles, case reports, use of the same sample, absence of case or control groups (as control group was considered any diagnosis of benign thyroid lesions, such as: goiter, follicular adenoma, thyroiditis, hyperplasic nodules or normal thyroid samples), fewer than 12 patients in each group (both case and control), individuals under 18 years, use of any organ other than thyroid, use of any marker other than CK-19, Gal-3 or HBME-1, inclusion of another histological malignant type other than the welldifferentiated thyroid carcinoma, use of techniques other than immunocytochemistry or immunohistochemistry, use of specimens other than human, use of specimens other than those obtained exclusively from the thyroid gland (for example, blood and derivatives).

The data from the studies was independently collected by two researchers, who employed a standardized form. The following information was extracted: reference, number of patients in the case and control groups, technique employed (immunocytochemistry or immunohistochemistry), histological types of neoplasias studied and results (stratified into four groups: truepositive; false-positive; false-negative; and true-negative). Differences in the data extracted were resolved by group consensus.

Initially, 265 abstracts were selected and, after applying the established criteria above, 66 articles were included

Table 3 Positive likelihood ratio (Positive LR) and negative likelihood ratio (Negative LR) of each immunohistochemistry marker and association

\begin{tabular}{lcccccc}
\hline IHC ANALYSIS & Positive LR (95\% Cl) & Q & P & Negative LR (95\% Cl) & Q & P \\
\hline CK-19[10,14-33] & $2.87(2.10-3.92)$ & 262.28 & $<0.00001$ & $0.25(0.18-0.35)$ & 131.17 & $<0.00001$ \\
GAL-3[10,14-17,19,21,25-56] & $4.24(3.08-5.82)$ & 605.28 & $<0.00001$ & $0.21(0.15-0.30)$ & 508.27 & $<0.00001$ \\
HBME-1[10,14-19,21,24-27,29,30,41,51,57-61] & $6.93(4.42-10.88)$ & 355.63 & $<0.00001$ & $0.22(0.16-0.30)$ & 234.36 & $<0.00001$ \\
CK-19+ HBME-1[14,17] & $16.71(0.38-742.57)$ & 6.35 & 0.0118 & $0.16(0.10-0.25)$ & 0.11 & 0.7385 \\
GAL-3+ CK-19[14,17] & $8.49(1.04-69.17)$ & 6.83 & 0.0089 & $0.10(0.05-0.19)$ & 0.15 & 0.6943 \\
GAL-3+ HBME-1[14,17,46,51] & $4.92(1.70-14.27)$ & 13.48 & 0.0037 & $0.23(0.03-1.70)$ & 107.69 & $<0.00001$ \\
GAL-3+ HBME-1 + CK-19[14,17,29] & $17.19(3.36-87.96)$ & 3.69 & 0.1577 & $0.17(0.11-0.24)$ & 0.10 & 0.9508 \\
\hline
\end{tabular}


Table 4 Diagnostic odds ratio (dOR) calculated for each immunohistochemistry marker or combination

\begin{tabular}{lccc}
\hline IHC ANALYSIS & dOR $(\mathbf{9 5} \%$ Cl) & Q & P \\
\hline CK-19[10,14-33] & $14.73(8.20-26.45)$ & 110.05 & $<0.00001$ \\
GAL-3[10,14-17,19,21,25-56] & $23.41(14.02-39.07)$ & 252.72 & $<0.00001$ \\
HBME-1[10,14-19,21,24-27,29,30,41,51,57-61] & $40.97(21.42-78.37)$ & 140.82 & $<0.00001$ \\
CK-19+ HBME-1[14,17] & $119.06(6.81-2080.37)$ & 2.62 & 0.1058 \\
GAL-3+ CK-19[14,17] & $86.54(10.8-693.52)$ & 21.16 & 0.8292 \\
GAL-3 + HBME-1[14,17,46,51] & $21.94(2.88-167.49)$ & 2.23 & 0.0001 \\
GAL-3 + HBME-1 + CK-19[14,17,29] & $95.06(25.17-359.08)$ & 0.3280 \\
\hline
\end{tabular}

in the meta-analysis itself with 5,168 patients, as shown in Figure 1.

\section{Meta-analysis}

The Meta-DiSc ${ }^{\circledR}$ Program (Clinical BioStatistics Unit Hospital Ramón y Cajal, Madrid, Spain) was employed in all the analyses [12]. The method applied was the meta-analysis of diagnostic tests of independent studies stratified according to the size of the sample in each study, using Mantel-Haenszel's method: a fixed effect estimated from the size of each study calculated by the inverse of its variance. The random effect of each study was established by the DerSimonian-Lair method and the presence of heterogeneity among the studies was estimated by the Cochrans Q-Test and was considered significant when $\mathrm{P}<0.1$.

Values of sensitivity, specificity, positive and negative likelihood ratios, as well as their confidence intervals (95\% CI), were calculated separately for each study and also for the studies grouped according to the type of marker or associations. Forest-plots of the most relevant results were performed.
The diagnostic odds ratio (dOR) was also calculated. It is an additional measure that expresses the accuracy of the test and represents how much greater the chance of achieving exactitude is when the test is positive as opposed to when the test is negative.

Complementarily, ROC (Receiver Operating Characteristic) analysis was done and areas under the summary ROC curves were calculated. This method is different from conventional ROC analysis, which compares test accuracy over different thresholds for positivity, because in an SROC graph each data point comes from a different study, but diagnostic thresholds should be similar for each study so as not to influence the shape of the curve [13].

\section{Results}

The analyses of diagnostic accuracy of markers CK-19, Gal-3 and HBME-1, and their associations, in the differentiation of well-differentiated carcinoma and benign thyroid lesions, were evaluated separately by the immunohistochemistry and immunocytochemistry techniques, as described below.

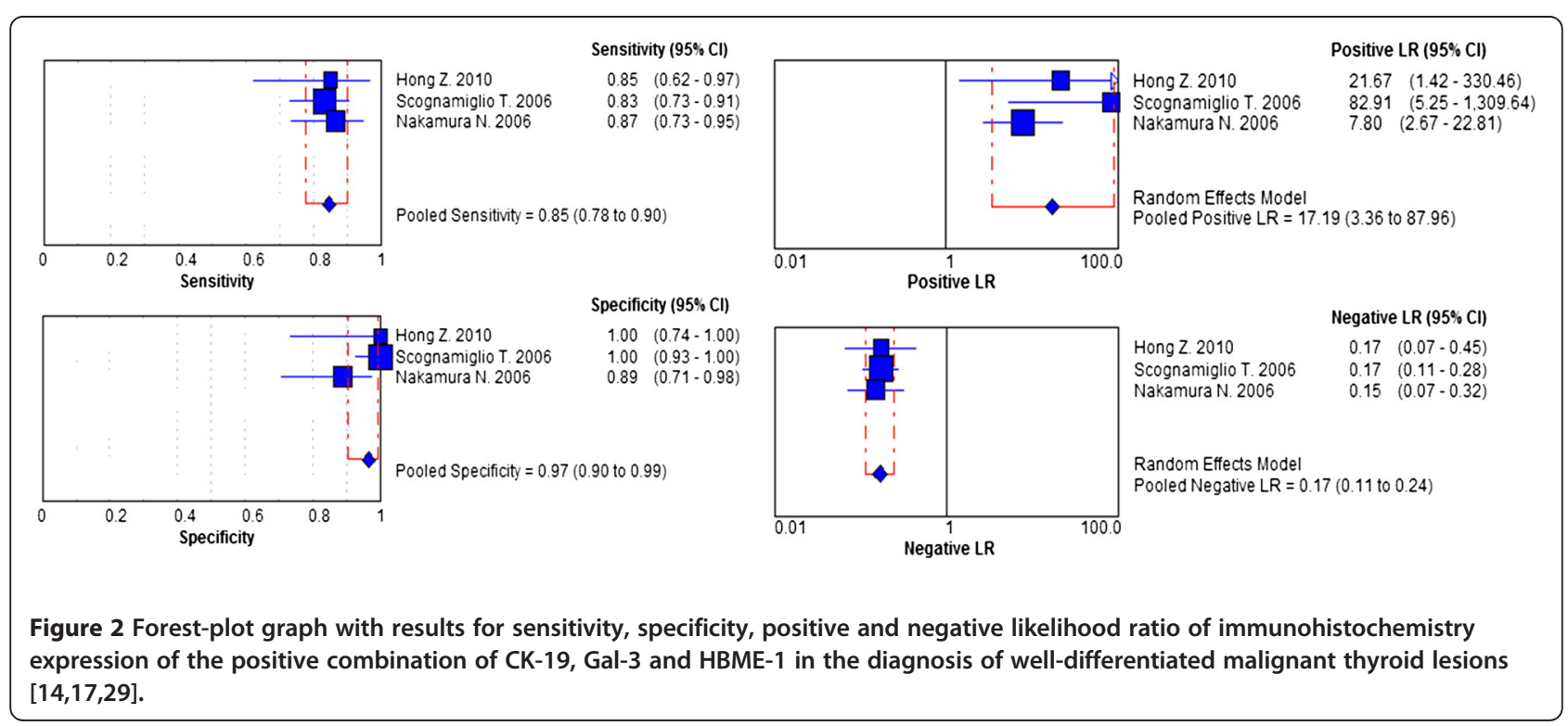


Table 5 Number of studies, patients and their distributions included in each analysis, for the immunocytochemistry technique

\begin{tabular}{lcccrrr}
\hline ICC ANALYSIS & STUDIES & PATIENTS & TP & FP & FN & TN \\
\hline CK-19[31,62,63] & 3 & 230 & $111(48.3 \%)$ & $19(8.3 \%)$ & $27(11.7 \%)$ & $73(31.7 \%)$ \\
GAL-3[31,64-75] & 14 & 1785 & $581(33.9 \%)$ & $103(6.0 \%)$ & $104(6.0 \%)$ & $927(54.1 \%)$ \\
HBME-1[31,62,64,66,74,76,77] & 7 & 3900 & $1501(38.5 \%)$ & $324(8.3 \%)$ & $436(11.2 \%)$ & $1639(42.0 \%)$ \\
\hline
\end{tabular}

LEGEND: TP (true-positive), FP (false-positive), FN (false-negative) and TN (true-negative).

\section{Immunohistochemistry technique}

The present meta-analysis included 49 articles and 5168 patients in the broader analysis, with variable rates of true-positive and true-negative tests, and with a considerable rate of false results (Table 1 ).

The values for sensitivity, specificity, and likelihood ratios and their respective heterogeneity coefficients are detailed in Table 2 and Table 3. It was noted that these values are very discrepant and not so high when the immunomarkers are analyzed alone. Nonetheless, the association of markers can significantly increase the diagnostic rates but with an important loss of references.

Diagnostic odds ratio (dOR) was calculated directly from sensitivity and specificity values (Table 4). This measurement represents the overall diagnostic power of each test (a high dOR implies that the test shows good diagnostic accuracy in all patients) and, as seen, the test with greatest diagnostic accuracy and least inconsistency in the distinction between benign and malignant thyroid lesions is the positivity of the three combined markers (CK-19, Gal-3 and HBME-1). Thus, the forest-plot charts that summarize the individual results of the articles selected for this analysis in a global rate ("diamond" as pooling symbol) for sensitivity, specificity, positive and negative likelihood ratios are represented in Figure 2.

\section{Immunocytochemistry technique}

The same analysis was performed for the three markers with the exclusive aim of making a preoperative diagnosis of thyroid lesions. However, the combination of markers suitable for the application of meta-analysis was not identified in the literature and the results were only based on the individual expression of each molecule.

This analysis included 17 articles with a special focus on HBME-1 analysis with 3900 samples included. Falsenegative and false-positive rates were significant, and diagnostic results showed that Galectin-3 had low negative LR and high sensitivity, specificity and positive LR with the highest diagnostic odds ratio, an analysis with less heterogeneity; demonstrating that this marker is the best at making a preoperative distinction between benign and malignant thyroid lesions. The results are described in Tables 5, 6, 7, and 8 .

\section{Exploring heterogeneity}

The first factor of heterogeneity loss in the analyses employing the immunohistochemistry technique was the combination of markers, as previously shown. Therefore, it became clear that none of these molecules, when studied independently, can reliably differentiate between benign and well-differentiated malignant tumors of the thyroid.

Therefore, in a search for other factors involved in the determination of heterogeneity causes, the following possible confounding variables were evaluated: inclusion of oncocytic or Hürthle cells in the sample and/or the criterion adopted to consider a marker as "positive".

When both techniques (imunocytochemistry and immunohistochemistry) are considered, the review of the selected studies indicated that some authors actually included oncocytic patterned tumors (or Hürthle cell neoplasias) in their samples. Hürthle cells are characterized by their wide and granular cytoplasm and, besides, most oncocytic lesions at cytology are shown to be benign lesions upon histopathological examination (Hürthle cell adenomas, hyperplastic nodules, thyroiditis and Graves' disease), the mere presence of these cells in a cytological exam indicates a greater likelihood of malignancy (Bethesda IV), regardless of other criteria [78]. These factors make an exact etiological preoperative diagnosis of these neoplasms even more difficult [79].

It was also observed that in some studies the immunostaining was considered to be positive when at least $5 \%$ of the cells expressed the marker, whereas this minimum percentage was considered by others to be $10 \%$,

Table 6 Sensitivity and specificity of each immunocytochemistry marker

\begin{tabular}{lccccrr}
\hline ICC ANALYSIS & Sensitivity (95\% CI) & Q & P & Specificity (95\% Cl) & Q & P \\
\hline CK-19[31,62,63] & $0.80(0.73-0.87)$ & 63.04 & $<0.00001$ & $0.79(0.70-0.87)$ & 23.50 & $<0.00001$ \\
GAL-3[31,64-75] & $0.85(0.83-0.88)$ & 64.53 & $<0.00001$ & $0.90(0.88-0.92)$ & 48.39 & $<0.00001$ \\
HBME-1[31,62,64,66,74,76,77] & $0.83(0.79-0.86)$ & 15.30 & 0.0180 & $0.79(0.75-0.84)$ & 48.62 & $<0.00001$ \\
\hline
\end{tabular}


Table 7 Ratios of positive likelihood (Positive LR) and of negative likelihood (Negative LR) of each immunocytochemistry marker

\begin{tabular}{lcccccc}
\hline ICC ANALYSIS & Positive LR (95\% CI) & Q & P & Negative LR (95\% Cl) & Q & P \\
\hline CK-19[31,62,63] & $(0.80-33.17)$ & 28.16 & $<0.00001$ & $0.26(0.18-0.36)$ & 1.48 & 0.4765 \\
GAL-3[31,64-75] & $7.73(5.54-10.79)$ & 40.40 & 0.0001 & $0.15(0.09-0.22)$ & 65.52 & $<0.00001$ \\
HBME-1[31,62,64,66,74,76,77] & $6.71(2.92-15.44)$ & 52.38 & $<0.00001$ & $0.20(0.14-0.30)$ & 15.62 & 0.0159 \\
\hline
\end{tabular}

$25 \%$, or even $50 \%$. Also, when the immunostaining was weak, heterogeneous or sometimes even focal, it was likewise, considered positive.

Thus, when the combination of markers was then analyzed (only for immunohistochemistry analysis), and after removing Hürthle cells from the data and reclassifying the cases with a percentage of immunostained cells below $25 \%$, weak or focal marking as "negative", it was possible to exclude the previously noted heterogeneity from the groups (data not shown). SROC curves were plotted at this time to thresholds of the different studies to make them more similar and to better illustrate these results (immunohistochemistry - Figure 3 and immunocytochemistry - Figure 4). However, when these same variables were excluded and a new analysis of CK-19, Gal-3 and HBME-1 was undertaken separately, there was always the presence of unequivocal heterogeneity for the immunohistochemical technique. As the metaanalysis was performed exclusively on published studies and did not use the authors' original data, in some instances the criteria described above could not be applied with certainty; thus, these articles were excluded from the analysis.

\section{Discussions}

The preoperative diagnosis of thyroid lesions is not the only challenge faced by pathologists. Very often, establishing the differential diagnosis between benignancy and malignancy of a thyroid nodule, based only on the histopathological exam, can be quite difficult.

One of the greatest research challenges involving welldifferentiated thyroid carcinoma is to develop a method to enable the correct differential diagnosis between benign and malignant lesions, trying to avoid a diagnostic surgery. To really reach this objective a test would need to have an especially high sensitivity rate,[11] but it has not yet been achieved in the literature even when genomic classifiers are employed [80]. Thus, the search for

Table 8 Diagnostic odds ratio (dOR) calculated for each immunocytochemistry marker

\begin{tabular}{lcrc}
\hline ICC ANALYSIS & dOR $(\mathbf{9 5 \%} \mathbf{C I})$ & $\mathbf{Q}$ & $\mathbf{p}$ \\
\hline CK-19[31,62,63] & $30.31(12.64-72.66)$ & 0.46 & 0.7954 \\
GAL-3[31,64-75] & $64.18(36.26-113.61)$ & 31.98 & 0.0024 \\
HBME-1[31,62,64,66,74,76,77] & $42.28(13.02-137.28)$ & 34.44 & $<0.00001$ \\
\hline
\end{tabular}

a "marker" that enhances this diagnostic capability is ongoing [81].

Cytokeratin-19 (CK-19) expression in thyroid nodules is in general intense and diffuse in papillary carcinoma and heterogeneous labeling in carcinoma and in follicular adenoma, with nil or low expression in other benign lesions [30,82]. Galectins, especially galectin-3, are suggested to play a role in the pathogenesis of welldifferentiated thyroid carcinoma, particularly in papillary carcinoma[83] and, therefore, it is one of the markers most commonly used to assist in distinguishing thyroid lesions. Hector Battifora mesothelial-1 (HBME-1) has been demonstrated to be important as a thyroid marker of follicular origin, with greater affinity to malignant lesions when compared to benign lesions[84]. Because of that, they are the three most used immunomarkers in pathology practice and each of them had different rates of false-negatives and false-positive results and some authors advocate that a panel of the three markers might be more helpful than the use of a single immunomarker, improving the specificity, positive and negative predictive value and thus diagnostic accuracy [85].

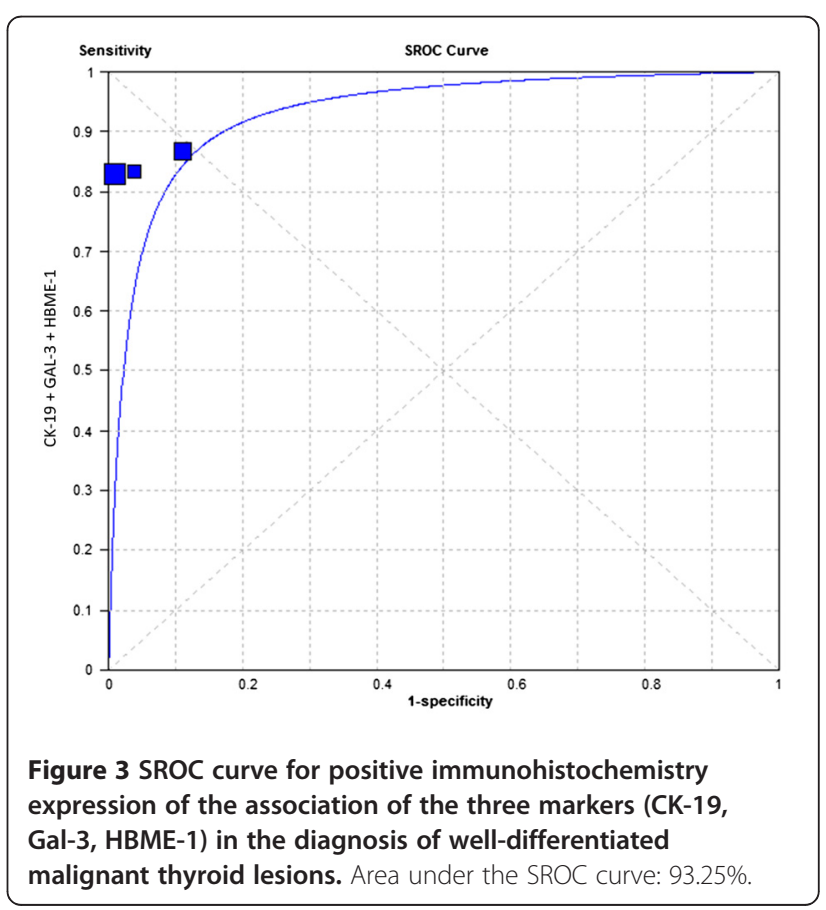



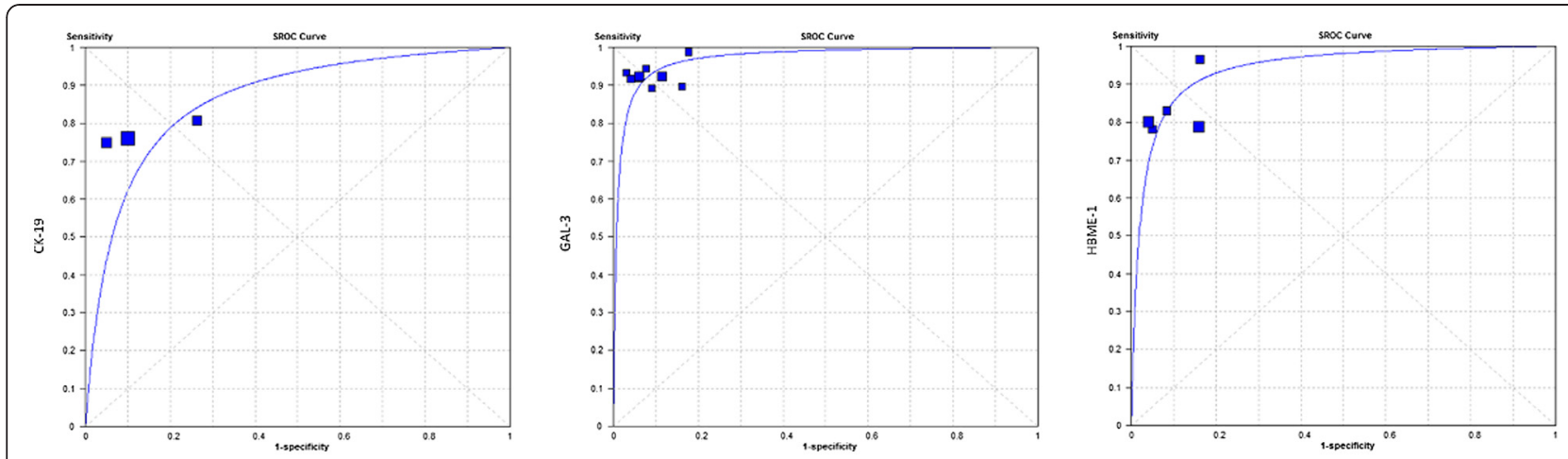

Figure 4 SROC curve for positive immunocytochemistry expression of CK-19, Gal-3 and HBME-1 in the diagnosis of well-differentiated malignant lesions of the thyroid. Areas under the SROC curve: CK-19=86.32\%; Gal-3=97.07\%; HBME-1=94.12\%.

The main contribution of this meta-analysis was to precisely quantify the accuracy of values of these three important markers employed in clinical practice. Several literature reviews have already been published but the present study is the first to analyze cumulative data and is worthy for this reason.

As demonstrated, the association of positivity for CK19, Gal-3 and HBME-1 in IHC assays and the preoperative expression of galectin-3 in ICC samples proved to be highly accurate tests in the distinction between benign and well-differentiated thyroid carcinoma. This is further noted when heterogeneity factors were disregarded; the SROC analysis showed a global accuracy of more than $90 \%$ in this situation.

However, these results must be analyzed with great care. Despite the fact that the accuracy rates are, in general, high there is a considerable percentage of falseresults. When a diagnostic test could potentially produce a false-negative result this is not a good reason to take a watchful waiting approach, especially when a malignant neoplasm is the object of the study, and many patients are subjected to a theoretically unnecessary diagnostic surgery, with associated morbidity and mortality rates.

Another important point of this study was the determination of heterogeneity variables involved in the analysis of tumors markers employed in thyroid nodule diagnosis. Thus, the combination of markers, the exclusion of Hürthle cells and the review of what must be considered positive immunostaining were the main heterogeneity factors identified. Another possible heterogeneity factor that might be considered and that was not possible to evaluate in this research has to do with the technical methodology applied in the immunohistochemical reactions like specimen fixation, monoclonal or polyclonal antibodies, biotin-free detection method, etc. These parameters should be standardized in future works in order to achieve uniformity in the studies and improvement in diagnostic accuracy of the immunocytochemistry and immunohistochemistry methods.
Nevertheless, this study has some limitations. The present review might have been influenced by publication bias since it was limited to articles in English and included only published articles. However, the wide search criteria applied and the rigorous exclusion criteria have helped to ensure the inclusion of the most relevant studies.

In summary, this meta-analysis demonstrated that the three studied immunomarkers are accurate in making a pre- and postoperative distinction between benign and malignant thyroid lesions with accuracy of around 90\% for both immunocytochemistry and immunohistochemistry assays, despite avoiding variables responsible for heterogeneity in the analysis. Although, the search for other molecular markers must continue in order to enhance this diagnostic accuracy since the results found still show persistency of false-negative and false-positive tests.

\section{Competing interests}

The authors declare that they have no competing interests.

\section{Authors' contributions}

ABG, COM, MLF and LLM performed the systematic review and article selection. LLM participated in the design of the study, performed the statistical analysis and wrote the manuscript. AG and MASP conceived the study, and participated in its design and coordination and helped to draft the manuscript. All authors read and approved the final manuscript.

\section{Acknowledgments}

The authors are grateful to FAPESP (Fundação de Amparo à Pesquisa do Estado de São Paulo), CAPES (Coordenação de Aperfeiçoamento de Pessoal de Nível Superior) and CNPq (Conselho Nacional de Desenvolvimento Científico e Tecnológico) for technical and financial support.

\section{Author details}

${ }^{1}$ Biochemistry Department - Faculdade de Medicina do ABC, Santo André, Brazil. ${ }^{2}$ Biochemistry Department - Universidade Federal de São Paulo, São Paulo, Brazil. ${ }^{3}$ Head and Neck Surgery Department - Faculdade de Medicina do ABC, Santo André, Brazil. ${ }^{4}$ Medical School Students - Faculdade de Medicina do ABC, Santo André, Brazil. ${ }^{5}$ Chairman of Hematology and Oncology Department - Faculdade de Medicina do ABC, Santo André, Brazil; Medical Oncologist - Albert Einstein Jewish Hospital, São Paulo, Brazil. ${ }^{6}$ Rua São Paulo, 1670, Ap.41, ZIP: 09541-100, São Caetano do Sul, SP, Brazil.

Received: 20 May 2012 Accepted: 6 August 2012

Published: 13 August 2012 


\section{References}

1. Jemal A, Siegel R, Xu J, Ward E: Cancer statistics, 2010. CA Cancer J Clin 2010, 60:277-300.

2. Gonzalez-Yebra B, Peralta R, Gonzalez AL, Ayala-Garcia MA, de Zarate ME O, Salcedo M: Genetic alterations in a primary medullary thyroid carcinoma and its lymph node metastasis in a patient with 15 years follow-up. Diagn Pathol 2012, 7:63.

3. Peccin S, de Castsro JA, Furlanetto TW, Furtado AP, Brasil BA, Czepielewski MA: Ultrasonography: is it useful in the diagnosis of cancer in thyroid nodules? J Endocrinol Invest 2002, 25:39-43.

4. Tomimori EK, Bisi H, Medeiros-Neto G, Camargo RY: Ultrasonographic evaluation of thyroid nodules: comparison with cytologic and histologic diagnosis. Ara Bras Endocrinol Metabol 2004, 48:105-113.

5. Utiger RD: The multiplicity of thyroid nodules and carcinomas. N Engl J Med 2005, 352:2376-2378.

6. Schlumberger MJ: Papillary and follicular thyroid carcinoma. N Engl I Med 1998, 338:297-306

7. LiVolsi VA, Baloch ZW: Follicular neoplasms of the thyroid: view, biases, and experiences. Adv Anat Pathol 2004, 11:279-287.

8. Zeiger MA, Dackiw AP: Follicular thyroid lesions, elements that affect both diagnosis and prognosis. J Surg Oncol 2005, 89:108-113.

9. Matsuo SE, Martins L, Leoni SG, Hajjar D, Ricarte-Filho JC, Ebina KN, Kimura ET: Biological markers in thyroid tumors. Ara Bras Endocrinol Metabol 2004, 48:114-125

10. Barroeta JE, Baloch ZW, Lal P, Pasha TL, Zhang PJ, LiVolsi VA: Diagnostic value of differential expression of CK19, Galectin-3, HBME-1, ERK, RET, and $\mathrm{p} 16$ in benign and malignant follicular-derived lesions of the thyroid: an immunohistochemical tissue microarray analysis. Endocr Pathol 2006, 17:225-234.

11. Alexander EK, Kennedy GC, Baloch ZW, Cibas ES, Chudova D, Diggans J, Friedman L, Kloos RT, Livolsi VA, Mandel SJ, et al: Preoperative Diagnosis of Benign Thyroid Nodules with Indeterminate Cytology. N Engl J Med 2012, Epub ahead of print

12. Zamora J, Abraira V, Muriel A, Khan K, Coomarasamy A: Meta-DiSc: a software for meta-analysis of test accuracy data. BMC Med Res Methodol 2006, 6:31

13. Jones CM, Athanasiou T: Summary receiver operating characteristic curve analysis techniques in the evaluation of diagnostic tests. Ann Thorac Surg 2005, 79:16-20.

14. Hong Z, Qi JP, Wang YW, Song YJ, Zhang ZY: Hyalinizing trabecular tumor and papillary carcinoma of the thyroid. Chin Med I (Engl) 2010 123:2832-2835.

15. Zhu X, Sun T, Lu H, Zhou X, Lu Y, Cai X: Diagnostic significance of CK19, RET, galectin-3 and HBME-1 expression for papillary thyroid carcinoma. J Clin Pathol 2010, 63:786-789.

16. Park YJ, Kwak SH, Kim DC, Kim H, Choe G, do Park J, Jang HC, Park SH, Cho BY, Park SY: Diagnostic value of galectin-3, HBME-1, cytokeratin 19, high molecular weight cytokeratin, cyclin D1 and p27(kip1) in the differential diagnosis of thyroid nodules. J Korean Med Sci 2007, 22:621-628.

17. Scognamiglio T, Hyjek E, Kao J, Chen YT: Diagnostic usefulness of HBME1, galectin-3, CK19, and CITED1 and evaluation of their expression in encapsulated lesions with questionable features of papillary thyroid carcinoma. Am J Clin Pathol 2006, 126:700-708.

18. Nasr MR, Mukhopadhyay S, Zhang S, Katzenstein AL: Immunohistochemical markers in diagnosis of papillary thyroid carcinoma: Utility of HBME1 combined with CK19 immunostaining. Mod Pathol 2006, 19:1631-1637.

19. Prasad ML, Pellegata NS, Huang Y, Nagaraja HN, de la Chapelle A, Kloos RT Galectin-3, fibronectin-1, CITED-1, HBME1 and cytokeratin-19 immunohistochemistry is useful for the differential diagnosis of thyroid tumors. Mod Pathol 2005, 18:48-57.

20. Cameron BR, Berean KW: Cytokeratin subtypes in thyroid tumours: immunohistochemical study with emphasis on the follicular variant of papillary carcinoma. J Otolaryngol 2003, 32:319-322.

21. Casey MB, Lohse CM, Lloyd RV: Distinction between papillary thyroid hyperplasia and papillary thyroid carcinoma by immunohistochemical staining for cytokeratin 19, galectin-3, and HBME-1. Endocr Pathol 2003, 14:55-60

22. Erkilic S, Aydin A, Kocer NE: Diagnostic utility of cytokeratin 19 expression in multinodular goiter with papillary areas and papillary carcinoma of thyroid. Endocr Pathol 2002, 13:207-211.
23. Sahoo S, Hoda SA, Rosai J, DeLellis RA: Cytokeratin 19 immunoreactivity in the diagnosis of papillary thyroid carcinoma: a note of caution. Am J Clin Pathol 2001, 116:696-702.

24. Cheung CC, Ezzat S, Freeman JL, Rosen IB, Asa SL: Immunohistochemical diagnosis of papillary thyroid carcinoma. Mod Pathol 2001, 14:338-342.

25. Barut F, Onak Kandemir N, Bektas S, Bahadir B, Keser S, Ozdamar SO: Universal markers of thyroid malignancies: galectin-3, HBME-1, and cytokeratin-19. Endocr Pathol 2010, 21:80-89.

26. Wiseman SM, Melck A, Masoudi H, Ghaidi F, Goldstein L, Gown A, Jones SJ, Griffith OL: Molecular phenotyping of thyroid tumors identifies a marker panel for differentiated thyroid cancer diagnosis. Ann Surg Oncol 2008, 15:2811-2826.

27. Liu YY, Morreau H, Kievit J, Romijn JA, Carrasco N, Smit JW: Combined immunostaining with galectin-3, fibronectin-1, CITED-1, Hector Battifora mesothelial-1, cytokeratin-19, peroxisome proliferator-activated receptor\{gamma\}, and sodium/iodide symporter antibodies for the differential diagnosis of non-medullary thyroid carcinoma. Eur J Endocrinol 2008, 158:375-384.

28. Murphy KM, Chen F, Clark DP: Identification of immunohistochemical biomarkers for papillary thyroid carcinoma using gene expression profiling. Hum Pathol 2008, 39:420-426.

29. Nakamura N, Erickson LA, Jin L, Kajita S, Zhang H, Qian X, Rumilla K, Lloyd RV Immunohistochemical separation of follicular variant of papillary thyroid carcinoma from follicular adenoma. Endocr Pathol 2006, 17:213-223.

30. Rossi ED, Raffaelli M, Mule A, Miraglia A, Lombardi CP, Vecchio FM, Fadda G: Simultaneous immunohistochemical expression of HBME-1 and galectin3 differentiates papillary carcinomas from hyperfunctioning lesions of the thyroid. Histopathology 2006, 48:795-800.

31. Saggiorato E, De Pompa R, Volante M, Cappia S, Arecco F, Dei Tos AP, Orlandi F, Papotti M: Characterization of thyroid 'follicular neoplasms' in fine-needle aspiration cytological specimens using a panel of immunohistochemical markers: a proposal for clinical application. Endocr Relat Cancer 2005, 12:305-317.

32. Beesley MF, McLaren KM: Cytokeratin 19 and galectin-3 immunohistochemistry in the differential diagnosis of solitary thyroid nodules. Histopathology 2002, 41:236-243.

33. Song $Q$, Wang $D$, Lou Y, Li C, Fang C, He X, Li J: Diagnostic significance of CK19, TG, Ki67 and galectin-3 expression for papillary thyroid carcinoma in the northeastern region of China. Diagn Pathol 2011, 6:126.

34. Rydlova M, Ludvikova M, Stankova I: Potential diagnostic markers in nodular lesions of the thyroid gland: an immunohistochemical study. Biomed Pap Med Fac Univ Palacky Olomouc Czech Repub 2008, 152:53-59.

35. Raggio E, Camandona M, Solerio D, Martino P, Franchello A, Orlandi F, Gasparri G: The diagnostic accuracy of the immunocytochemical markers in the pre-operative evaluation of follicular thyroid lesions. J Endocrinol Invest 2010, 33:378-381.

36. Inohara H, Segawa T, Miyauchi A, Yoshii T, Nakahara S, Raz A, Maeda M, Miyoshi E, Kinoshita N, Yoshida H, et al: Cytoplasmic and serum galectin-3 in diagnosis of thyroid malignancies. Biochem Biophys Res Commun 2008 376:605-610.

37. Aiad HA, Kandil MA, Asaad NY, El-Kased AM, El-Goday SF: Galectin-3 immunostaining in cytological and histopathological diagnosis of thyroid lesions. J Egypt Natl Canc Inst 2008, 20:36-46.

38. Sapio MR, Guerra A, Posca D, Limone PP, Deandrea M, Motta M, Troncone $\mathrm{G}$, Caleo A, Vallefuoco P, Rossi G, et al: Combined analysis of galectin-3 and BRAFV600E improves the accuracy of fine-needle aspiration biopsy with cytological findings suspicious for papillary thyroid carcinoma. Endocr Relat Cancer 2007, 14:1089-1097.

39. Aron M, Kapila K, Verma K: Utility of galectin 3 expression in thyroid aspirates as a diagnostic marker in differentiating benign from malignant thyroid neoplasms. Indian J Pathol Microbiol 2006, 49:376-380.

40. Ito Y, Nakamura Y, Yoshida H, Tomoda C, Uruno T, Takamura Y, Miya A, Kobayashi K, Matsuzuka F, Kuma K, et al: Polo-like kinase 1 expression in medullary carcinoma of the thyroid: its relationship with clinicopathological features. Pathobiology 2005, 72:186-190.

41. de Matos PS, Ferreira AP, de Oliveira Facuri F, Assumpcao LV, Metze K, Ward LS: Usefulness of HBME-1, cytokeratin 19 and galectin-3 immunostaining in the diagnosis of thyroid malignancy. Histopathology 2005, 47:391-401.

42. Galusca B, Dumollard JM, Lassandre S, Niveleau A, Prades JM, Estour B, Peoc'h M: Global DNA methylation evaluation: potential complementary marker in differential diagnosis of thyroid neoplasia. Virchows Arch 2005, 447:18-23. 
43. Nucera C, Mazzon E, Caillou B, Violi MA, Moleti M, Priolo C, Sturniolo G, Puzzolo D, Cavallari V, Trimarchi F, Vermiglio F: Human galectin-3 immunoexpression in thyroid follicular adenomas with cell atypia. J Endocrinol Invest 2005, 28:106-112.

44. Weber KB, Shroyer KR, Heinz DE, Nawaz S, Said MS, Haugen BR: The use of a combination of galectin-3 and thyroid peroxidase for the diagnosis and prognosis of thyroid cancer. Am J Clin Pathol 2004, 122:524-531.

45. Oestreicher-Kedem Y, Halpern M, Roizman P, Hardy B, Sulkes J, Feinmesser $R$, Stern $Y$ : Diagnostic value of galectin-3 as a marker for malignancy in follicular patterned thyroid lesions. Head Neck 2004, 26:960-966.

46. Volante M, Bozzalla-Cassione F, DePompa R, Saggiorato E, Bartolazzi A, Orlandi F, Papotti M: Galectin-3 and HBME-1 expression in oncocytic cell tumors of the thyroid. Virchows Arch 2004, 445:183-188.

47. Torres-Cabala C, Panizo-Santos A, Krutzsch HC, Barazi H, Namba M, Sakaguchi M, Roberts DD, Merino MJ: Differential expression of $\mathrm{S} 100 \mathrm{C}$ in thyroid lesions. Int J Surg Pathol 2004, 12:107-115.

48. Kovacs RB, Foldes J, Winkler G, Bodo M, Sapi Z: The investigation of galectin-3 in diseases of the thyroid gland. Eur J Endocrinol 2003, 149:449-453.

49. Jakubiak-Wielganowicz M, Kubiak R, Sygut J, Pomorski L, Kordek R: Usefulness of galectin-3 immunohistochemistry in differential diagnosis between thyroid follicular carcinoma and follicular adenoma. Pol J Pathol 2003, 54:111-115.

50. Giannini R, Faviana P, Cavinato T, Elisei R, Pacini F, Berti P, Fontanini G, Ugolini C, Camacci T, De leso K, et al: Galectin-3 and oncofetal-fibronectin expression in thyroid neoplasia as assessed by reverse transcriptionpolymerase chain reaction and immunochemistry in cytologic and pathologic specimens. Thyroid 2003, 13:765-770.

51. Nikiforova MN, Lynch RA, Biddinger PW, Alexander EK, Dorn GW 2nd, Tallini $G$, Kroll TG, Nikiforov YE: RAS point mutations and PAX8-PPAR gamma rearrangement in thyroid tumors: evidence for distinct molecular pathways in thyroid follicular carcinoma. J Clin Endocrinol Metab 2003, 88:2318-2326.

52. Gaffney RL, Carney JA, Sebo TJ, Erickson LA, Volante M, Papotti M, Lloyd RV: Galectin-3 expression in hyalinizing trabecular tumors of the thyroid gland. Am J Surg Pathol 2003, 27:494-498.

53. Martins L, Matsuo SE, Ebina KN, Kulcsar MA, Friguglietti CU, Kimura ET: Galectin-3 messenger ribonucleic acid and protein are expressed in benign thyroid tumors. J Clin Endocrinol Metab 2002, 87:4806-4810.

54. Coli A, Bigotti G, Zucchetti F, Negro F, Massi G: Galectin-3, a marker of well-differentiated thyroid carcinoma, is expressed in thyroid nodules with cytological atypia. Histopathology 2002, 40:80-87.

55. Nascimento MC, Bisi H, Alves VA, Longatto-Filho A, Kanamura CT, MedeirosNeto G: Differential reactivity for galectin-3 in Hurthle cell adenomas and carcinomas. Endocr Pathol 2001, 12:275-279.

56. Lavra L, Rinaldo C, Ulivieri A, Luciani E, Fidanza P, Giacomelli L, Bellotti C, Ricci A, Trovato M, Soddu S, et al: The loss of the p53 activator HIPK2 is responsible for galectin-3 overexpression in well differentiated thyroid carcinomas. PLoS One 2011, 6:e20665.

57. Mai KT, Bokhary R, Yazdi HM, Thomas J, Commons AS: Reduced HBME-1 immunoreactivity of papillary thyroid carcinoma and papillary thyroid carcinoma-related neoplastic lesions with Hurthle cell and/or apocrinelike changes. Histopathology 2002, 40:133-142.

58. Ozolins A, Narbuts Z, Strumfa I, Volanska G, Gardovskis J: Diagnostic utility of immunohistochemical panel in various thyroid pathologies. Langenbecks Arch Surg 2010, 395:885-891.

59. Liang HS, Zhong YH, Luo ZJ, Huang Y, Lin HD, Luo M, Su HX, Zhou SB, Xie $\mathrm{KQ}$ : Comparative analysis of protein expression in differentiated thyroid tumours: a multicentre study. J Int Med Res 2009, 37:927-938.

60. Ito Y, Yoshida H, Tomoda C, Miya A, Kobayashi K, Matsuzuka F, Kakudo K, Kuma K, Miyauchi A: HBME-1 expression in follicular tumor of the thyroid: an investigation of whether it can be used as a marker to diagnose follicular carcinoma. Anticancer Res 2005, 25:179-182.

61. Mase T, Funahashi H, Koshikawa T, Imai T, Nara Y, Tanaka Y, Nakao A: HBME1 immunostaining in thyroid tumors especially in follicular neoplasm. Endocr J 2003, 50:173-177.

62. Schmitt AC, Cohen C, Siddiqui MT: Paired box gene 8, HBME-1, and cytokeratin 19 expression in preoperative fine-needle aspiration of papillary thyroid carcinoma: diagnostic utility. Cancer Cytopathol 2010, 118:196-202.
63. Bonzanini M, Amadori PL, Sagramoso C, Dalla Palma P: Expression of cytokeratin 19 and protein $\mathrm{p} 63$ in fine needle aspiration biopsy of papillary thyroid carcinoma. Acta Cytol 2008, 52:541-548.

64. Torregrossa L, Faviana P, Filice ME, Materazzi G, Miccoli P, Vitti P, Fontanini G, Melillo RM, Santoro M, Basolo F: CXC chemokine receptor 4 immunodetection in the follicular variant of papillary thyroid carcinoma: comparison to galectin-3 and hector battifora mesothelial cell-1. Thyroid 2010, 20:495-504.

65. Pennelli G, Mian C, Pelizzo MR, Naccamulli D, Piotto A, Girelli ME, Mescoli C, Rugge M: Galectin-3 cytotest in thyroid follicular neoplasia: a prospective, monoinstitutional study. Acta Cytol 2009, 53:533-539.

66. Franco C, Martinez V, Allamand JP, Medina F, Glasinovic A, Osorio M Schachter D: Molecular markers in thyroid fine-needle aspiration biopsy: a prospective study. Appl Immunohistochem Mol Morphol 2009, 17:211-215.

67. Bartolazzi A, Orlandi F, Saggiorato E, Volante M, Arecco F, Rossetto R, Palestini N, Ghigo E, Papotti M, Bussolati G, et al: Galectin-3-expression analysis in the surgical selection of follicular thyroid nodules with indeterminate fine-needle aspiration cytology: a prospective multicentre study. Lancet Oncol 2008, 9:543-549.

68. Carpi A, Naccarato AG, lervasi G, Nicolini A, Bevilacqua G, Viacava P, Collecchi P, Lavra L, Marchetti C, Sciacchitano S, Bartolazzi A: Large needle aspiration biopsy and galectin-3 determination in selected thyroid nodules with indeterminate FNA-cytology. Br J Cancer 2006, 95:204-209.

69. Kim MJ, Kim HJ, Hong SJ, Shong YK, Gong G: Diagnostic utility of galectin3 in aspirates of thyroid follicular lesions. Acta Cytol 2006, 50:28-34.

70. Collet JF, Hurbain I, Prengel C, Utzmann O, Scetbon F, Bernaudin JF, Fajac A: Galectin-3 immunodetection in follicular thyroid neoplasms: a prospective study on fine-needle aspiration samples. Br J Cancer 2005 93:1175-1181

71. Maruta J, Hashimoto H, Yamashita H, Noguchi S: Immunostaining of galectin-3 and CD44v6 using fine-needle aspiration for distinguishing follicular carcinoma from adenoma. Diagn Cytopathol 2004, 31:392-396

72. Aratake $Y$, Umeki K, Kiyoyama K, Hinoura Y, Sato S, Ohno A, Kuribayashi T, Hirai K, Nabeshima K, Kotani T: Diagnostic utility of galectin-3 and CD26/ DPPIV as preoperative diagnostic markers for thyroid nodules. Diagn Cytopathol 2002, 26:366-372

73. Bartolazzi A, Gasbarri A, Papotti M, Bussolati G, Lucante T, Khan A, Inohara H, Marandino F, Orlandi F, Nardi F, et al: Application of an immunodiagnostic method for improving preoperative diagnosis of nodular thyroid lesions. Lancet 2001, 357:1644-1650.

74. Rossi ED, Raffaelli M, Minimo C, Mule A, Lombardi CP, Vecchio FM, Fadda G: Immunocytochemical evaluation of thyroid neoplasms on thin-layer smears from fine-needle aspiration biopsies. Cancer 2005, 105:87-95.

75. Saggiorato E, Aversa S, Deandreis D, Arecco F, Mussa A, Puligheddu B, Cappia S, Conticello S, Papotti M, Orlandi F: Galectin-3: presurgical marker of thyroid follicular epithelial cell-derived carcinomas. J Endocrinol Invest 2004, 27:311-317.

76. Mijovic T, Gologan O, Rochon L, Hier M, Black MJ, Young J, Rivera J, Tamilia $M$, Payne RJ: Fine-needle aspiration biopsy of the thyroid: review of cytopathologic features predictive of malignancy. J Otolaryngol Head Neck surg 2009, 38:348-354

77. de Micco C, Savchenko V, Giorgi R, Sebag F, Henry JF: Utility of malignancy markers in fine-needle aspiration cytology of thyroid nodules: comparison of Hector Battifora mesothelial antigen-1, thyroid peroxidase and dipeptidyl aminopeptidase IV. Br J Cancer 2008, 98:818-823.

78. Giorgadze T, Rossi ED, Fadda G, Gupta PK, Livolsi VA, Baloch Z: Does the fine-needle aspiration diagnosis of "Hurthle-cell neoplasm/follicular neoplasm with oncocytic features" denote increased risk of malignancy? Diagn Cytopathol 2004, 31:307-312.

79. Alaedeen DI, Khiyami A, McHenry CR: Fine-needle aspiration biopsy specimen with a predominance of Hurthle cells: a dilemma in the management of nodular thyroid disease. Surgery 2005, 138:650-656. discussion 656-657.

80. Eszlinger M, Paschke R: Molecular fine-needle aspiration biopsy diagnosis of thyroid nodules by tumor specific mutations and gene expression patterns. Mol Cell Endocrinol 2010, 322:29-37.

81. Kato MA, Fahey TJ 3rd: Molecular markers in thyroid cancer diagnostics. Surg Clin North Am 2009, 89:1139-1155. 
82. Baloch ZW, Abraham S, Roberts S, LiVolsi VA: Differential expression of cytokeratins in follicular variant of papillary carcinoma: an immunohistochemical study and its diagnostic utility. Hum Pathol 1999, 30:1166-1171.

83. Yoshii T, Inohara H, Takenaka Y, Honjo Y, Akahani S, Nomura T, Raz A, Kubo T: Galectin-3 maintains the transformed phenotype of thyroid papillary carcinoma cells. Int J Oncol 2001, 18:787-792.

84. Saussez S, Glinoer D, Chantrain G, Pattou F, Carnaille B, Andre S, Gabius HJ, Laurent G: Serum galectin-1 and galectin-3 levels in benign and malignant nodular thyroid disease. Thyroid 2008, 18:705-712.

85. Nga ME, Lim GS, Soh CH, Kumarasinghe MP: HBME-1 and CK19 are highly discriminatory in the cytological diagnosis of papillary thyroid carcinoma. Diagn Cytopathol 2008, 36:550-556.

doi:10.1186/1746-1596-7-97

Cite this article as: de Matos et al.: Expression of ck-19, galectin- 3 and hbme-1 in the differentiation of thyroid lesions: systematic review and diagnostic meta-analysis. Diagnostic Pathology 2012 7:97.

\section{Submit your next manuscript to BioMed Central and take full advantage of:}

- Convenient online submission

- Thorough peer review

- No space constraints or color figure charges

- Immediate publication on acceptance

- Inclusion in PubMed, CAS, Scopus and Google Scholar

- Research which is freely available for redistribution 